\title{
Phytochemical constituents and antioxidant activities of some plants commonly used in Indian traditional diet
}

\author{
Ashwini Prabhu ${ }^{1}$, M. Madhushree ${ }^{2}$, Rekha Punchappady Devasya $^{1} *$ \\ ${ }^{1}$ Yenepoya Research Centre, Yenepoya University, Mangalore - 575 018, Karnataka, India. \\ ${ }^{2}$ Department of Postgraduate studies and Research in Biosciences, Mangalore University, Mangalagangothri - 574 199, Karnataka, India.
}

\author{
ARTICLE INFO \\ Article history: \\ Received on: 27/07/2015 \\ Revised on: 22/08/2015 \\ Accepted on: 17/09/2015 \\ Available online: 27/11/2015 \\ Key words: \\ Traditional Diet, Plant \\ extracts, Phytoconstituents, \\ Total antioxidant activity, \\ Reducing Power assay.
}

\begin{abstract}
Dietary antioxidants are known to play a key role in combating the cellular oxidative stress imposed by the free radicals as well as in inhibiting the undesirable changes in nutritional quality of food. The present investigation was designed to evaluate the in vitro antioxidant properties and the major phytoconstituents of some plants regularly used in Indian traditional diet. Methanolic extracts of Costus igneus, Foeniculum vulgare, Leucas aspera, Muntingia calabura, Physalis minima and Sauropus androgynus were prepared by maceration. Antioxidant activities were assessed using phosphomolybdenum method and ferric reducing power assays. Total antioxidant activities of methanolic extracts ranged between $4.89 \mu \mathrm{g} / \mathrm{ml}$ to $46.0 \mu \mathrm{g} / \mathrm{ml}$ ascorbic acid equivalents for the tested extracts. F. vulgare methanolic extract possessed maximum antioxidant activity. This investigation revealed the potential antioxidant activity of the tested extracts and therefore, their use in the regular diet will be helpful in combating free radical associated health effects. Also, antioxidant rich formulations can be prepared using these plant materials.
\end{abstract}

\section{INTRODUCTION}

The generation of Reactive Oxygen Species (ROS) has been considered as a significant criterion in complications induced by oxidative stress. Under normal circumstances, cellular physiology is regulated in such a way that the oxidative stress is combated by enhanced activity of intracellular antioxidant enzymes. However, under circumstances of cellular dysfunction, increased levels of ROS eventually lead to pathogenesis of certain disorders such as cardiovascular disease, cancer, diabetes, autism and aging. Prolonged oxidative stress can trigger apoptotic and necrotic pathways in cells.

ROS imposed stress activates downstream signaling molecules such as PI3K, PKC and MAPK, thereby phosphorylating the transcription factor $\mathrm{Nrf} 2$ which then binds the antioxidant responsive element within the genes encoding antioxidant enzymes (Circu and Aw, 2010). Oxidative damage imposed by ROS can be reduced by various enzymatic/nonenzymatic antioxidant entities.

\footnotetext{
* Corresponding Author

Dr. Rekha PD, Deputy Director, Yenepoya Research Centre Yenepoya University, Deralakatte, Mangalore - 575018 Karnataka, India.

E-mail: dydirectoryrc@yenepoya.edu.in, Tel: +918242224668,Ext: 2035
}

In addition, an adequate antioxidant status in the body can be maintained through the intake of dietary antioxidants (Lu et al., 2010). Many studies have indicated that increased cellular oxidative damage is associated with premature aging and early onset of certain disorders. ROS levels can be decreased with the use of dietary antioxidants (Rahman, 2007). An enormous interest is focused on the intake of natural antioxidants due to the toxicological concerns associated with the use of synthetic antioxidants.

Several efforts have identified certain plants as a source of antioxidants that can be used under circumstances of enhanced antioxidant demand. Major compounds belonging to phenolics, flavonoids, carotenoids, phytosterols and thiols present in the plants confer antioxidant activity to the plant products. Natural antioxidants in foods have attracted greater attention as they are presumed to be safe and potentially nutritional (Khalaf et al., 2008). Regular intake of antioxidants in the diet also has a role in modulating the lifestyle disorders and aging (Nunez et al.,2013). This investigation was designed to evaluate the antioxidant potential of certain commonly used plants in Indian traditional diet. Foeniculum vulgare (fennel) is a highly aromatic and flavorful herb with culinary and medicinal uses. Fennel seeds are used as flavoring materials in baked foods, meat, fish dishes, ice cream, alcoholic beverages and herb mixtures (Rather et al., 2012). 
The whole plant is consumed as a vegetable in many European and Asian countries (Kaur and Arora, 2009). Similarly, leaves of Leucas aspera are regularly used in North India as a fragrance aid for food materials and is also used in the treatment of inflammation, dyspepsia and jaundice (Ali et al., 2013). Muntingia calabura, commonly known as Singapore cherry, is consumed as fresh fruits by certain ethnic groups (Gomathi et al., 2013). Fruits of Physalis minima, commonly known as native gooseberry, are used in the preparation of sharbat and also are added to desserts, fruit preserves or dried raisins. It is a good source of vitamin $\mathrm{C}$ and is considered to be a purgative, diuretic and cure for spleen inflammations (Chothani and Vaghasiya, 2012). Sauropus androgynus, commonly known as vitamin leaves or star gooseberry is a perennial plant grown in India and leaves are used as salad or steamed, added to egg dishes, casseroles and prepared as chutney (Kanchanapoom et al., 2003). Costus igneus (Family: Costaceae) leaves are consumed for the management of diabetes as a dietary supplement. This herb is also encountered in market in dried form or ground powder (Satareddi and Nandibewoor, 2012). Hence, considering the beneficial effects of these plants, the antioxidant potential of $C$. igneus, $F$. vulgare, L. aspera, $M$. calabura, P. minima and $S$. androgynus were studied.

\section{MATERIALS AND METHODS}

\section{Chemicals}

Sodium dihydrogen phosphate crystals, sodium hydroxide pellets, disodium hydrogen phosphate anhydrous, potassium ferricyanide, potassium hydroxide pellets, ascorbic acid, pyridine, methanol, sulphuric acid, hydrochloric acid, ammomium molybdate tetrahydrate and potassium iodide were procured from Merck (India). Sodium nitroprusside dihydrate and ferric chloride anhydrous were obtained from HiMedia (India). All the chemicals used were of analytical grade.

\section{Plant materials}

Leaves of C. igneus, F. vulgare, L. aspera, M. calabura, $P$. minima and $S$. androgynus were collected from local environs of Mangalore, Karnataka. Plant identification was done according to database on medicinal plants used in Ayurveda (Sharma et al., 2000). Plants were washed, shade-dried and powdered using a kitchen blender. The plant materials were stored at $4{ }^{\circ} \mathrm{C}$ till use for further analyses.

\section{Extraction}

Methanolic extracts of the plant materials were prepared by macerating $10 \mathrm{~g}$ of the powder with $40 \mathrm{ml}$ methanol at room temperature using an orbital shaker. The suspension was filtered using Whatmann No. 1 filter paper. The filtrate was concentrated to obtain the extract.

\section{Preliminary phytochemical screening}

The extracts were subjected to preliminary phytochemical scrrening using the standard procedures (Raman,
2006) in order to determine the presence of alkaloids, carbohydrates, glycosides, saponins, steroids, proteins, phenolics and flavonoids.

\section{Total antioxidant activity}

Antioxidant activities of the extracts were evaluated using phosphomolybdenum method (Prieto et al., 1999). The assay is based on the reduction of Mo (VI)-Mo (V) by the extract and subsequent formation of a green phosphate/Mo (V) complex at an acidic $\mathrm{pH}$. Different concentrations of extracts were combined with $3 \mathrm{ml}$ of reagent solution ( $0.6 \mathrm{M}$ sulfuric acid, $28 \mathrm{mM}$ sodium phosphate and $4 \mathrm{mM}$ ammonium molybdate). Methanol was used as blank. The tubes containing the reaction solution were capped and incubated in a boiling water bath at $95{ }^{\circ} \mathrm{C}$ for $90 \mathrm{~min}$. After cooling to room temperature, the absorbance of the solution was measured at $695 \mathrm{~nm}$ using a spectrophotometer (UV 1800, Shimadzu, Japan). Total antioxidant activities of the tested extracts were expressed as $\mu \mathrm{g} / \mathrm{ml}$ ascorbic acid equivalents (AAE).

\section{Reducing Power assay}

The reducing power of the extracts was determined according to Oyaizu et al (1978). Different concentrations of the extracts in $1 \mathrm{ml}$ of distilled water were mixed with phosphate buffer (2.5 mL, 0.2 M, pH 6.6) and potassium ferricyanide (2.5 $\mathrm{mL}, 1 \%$ ). The reaction contents were incubated at $50{ }^{\circ} \mathrm{C}$ for 20 min. To this mixture, $2.5 \mathrm{ml}$ of trichloroacetic acid (10\%) was added and centrifuged at $3000 \mathrm{rpm}$ for $10 \mathrm{~min}$. The upper layer of the solution $(2.5 \mathrm{~mL})$ was mixed with distilled water $(2.5 \mathrm{~mL})$ and $\mathrm{FeCl}_{3}(0.5 \mathrm{~mL}, 0.1 \%)$ and the absorbance was measured at 700 $\mathrm{nm}$. Ascorbic acid was used as standard. Phosphate buffer ( $\mathrm{pH}$ 6.6) was used as blank. Ferric reducing powers of the extracts were expressed as $\mu \mathrm{g} / \mathrm{ml}$ AAE.

\section{RESULTS AND DISCUSSION}

\section{Preliminary phytochemical screening}

Preliminary phytochemical screening of the methanolic extracts indicated the presence of alkoloids in the extracts of $P$. minima, and $S$. androgynus whereas, phytosterols were present in the extracts of $C$. igneus, $F$. vulgare, L. aspera and $S$. androgynus. L. aspera extract also showed the presence of saponins. Phenolics and flavonoids were detected in the extract of $F$. vulgare.

\section{Total antioxidant activity}

Antioxidant activity of the methanolic extracts of plants increased in a concentration dependent manner (Figure 1). At lower tested concentrations (10 and $15 \mu \mathrm{g} / \mathrm{ml})$, the highest antioxidant activity was observed in P. minima (15.26 and 21.0 $\mu \mathrm{g} / \mathrm{ml}$ AAE) and $L$. aspera (15.25 and $19.0 \mu \mathrm{g} / \mathrm{ml}$ AAE) extracts. However, $F$. vulgare possessed the maximum antioxidant activity which ranged from 12.12 to $46.0 \mu \mathrm{g} / \mathrm{ml} \mathrm{AAE}$ for the tested concentrations of 10 to $25 \mu \mathrm{g} / \mathrm{ml}$. Other extracts also showed good antioxidant activity ranging from 18.6 to $40.0 \mu \mathrm{g} / \mathrm{ml}$ ascorbic acid equivalents at a concentration of $25 \mu \mathrm{g} / \mathrm{ml}$. 

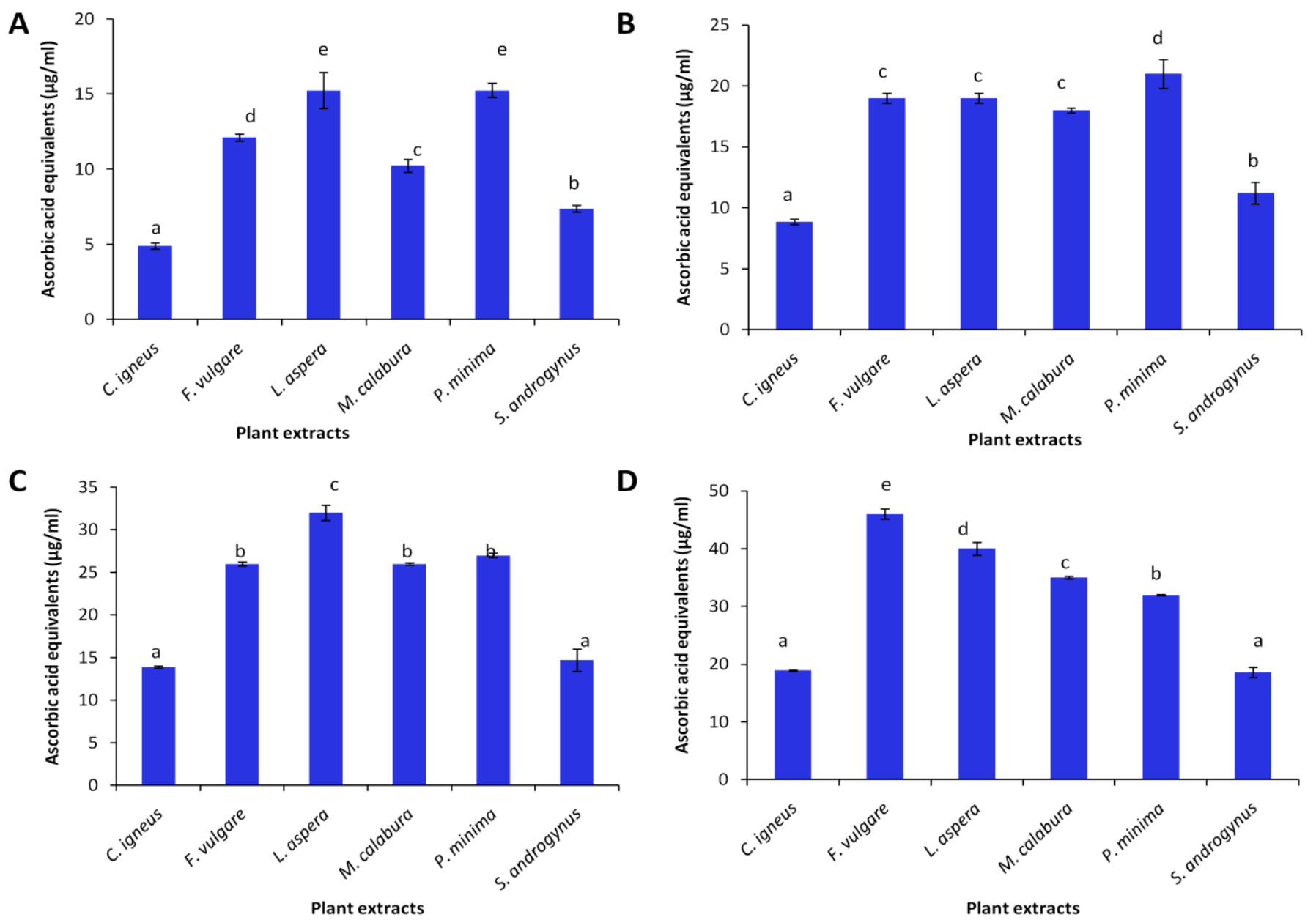

Fig. 1: Total antioxidant activity of tested extracts at (A) $10 \mu \mathrm{g} / \mathrm{ml}$ (B) $15 \mu \mathrm{g} / \mathrm{ml}$ (C) $20 \mu \mathrm{g} / \mathrm{ml}$ and (D) $25 \mu \mathrm{g} / \mathrm{ml}$ concentrations. Values are mean \pm SD ( $n=3$ ). Data points indicated by different alphabets are significantly different from each other $(p<0.01)$.

\section{Ferric Reducing Power}

Ferric reducing power of the tested extracts was found to follow a concentration dependent trend (Figure 2). Among the extracts studied, highest activity was present in $F$. vulgare, followed by $L$. aspera, M. calabura, P. minima, C. igneus and $S$. androgynus. At the highest tested concentration of $25 \mu \mathrm{g} / \mathrm{ml}, F$. vulgare extract showed a reducing activity of $60.18 \mu \mathrm{g} / \mathrm{ml}$ AAE which was $2.3 \%$ higher than that of the standard antioxidant ascorbic acid.

Among the methanolic extracts of the plants studied, $F$. vulgare extract showed maximum antioxidant activity which could be contributed to the presence of phytoconstituents such as phytosterols and flavonoids, which are well known to possess antioxidant activity (Rather et al., 2012). The free radical scavenging activity of the flavonoids are reported both in vitro and in vivo. Even though most ingested flavonoids are degraded into phenolic acids in vivo, their antioxidant activity was found to persist still. Absorbed flavonoids and their metabolites displayed antioxidant activity evidenced by increase of plasma antioxidant status in vivo (Pietta, 2000). Acetone and petroleum ether extracts of $F$. vulgare are known to possess potent activity against malodialdehyde production and this property was attributed to the presence of cis-miyabenol $\mathrm{C}$, d-limonene and fenchone (Purkayastha et al., 2012). Phenolic compounds from fennel including rosemarinic acid, quercetin and kaempferol are known for their antioxidant properties (Parejo et al., 2004). Ethanolic extract of $L$. aspera was found to be a potent DPPH free radical scavenger, which was attributed to the presence of nectandrin B, apigenin, myristagenol-B and licarin in it (Sadhu et al., 2003). Chloroform extracts of $M$. calabura were reported to be rich in polyphenolics, steroids and flavonoids and have been shown to exert strong ferric ion reducing activity (Sindhe et al., 2013). The presence of triterpenoids and polyphenolics in $P$. minima extract was correlated with its antioxidant activity (Karpagasundari and Kulothungan, 2014). The activity reported in this study by the plants are higher than that reported for Mimusops elengi (Saha et al., 2008), Acanthus ilicifolius, Suaeda meritima and Avicennia alba which are known for their antioxidant activities (Banerjee et al., 2008). C. igneus and S. androgynus extracts also displayed good activity due to the presence of alkaloids and phytosterols. The antioxidant activities displayed by the studied plants can be attributed to more than one class of phytocompounds. 
A

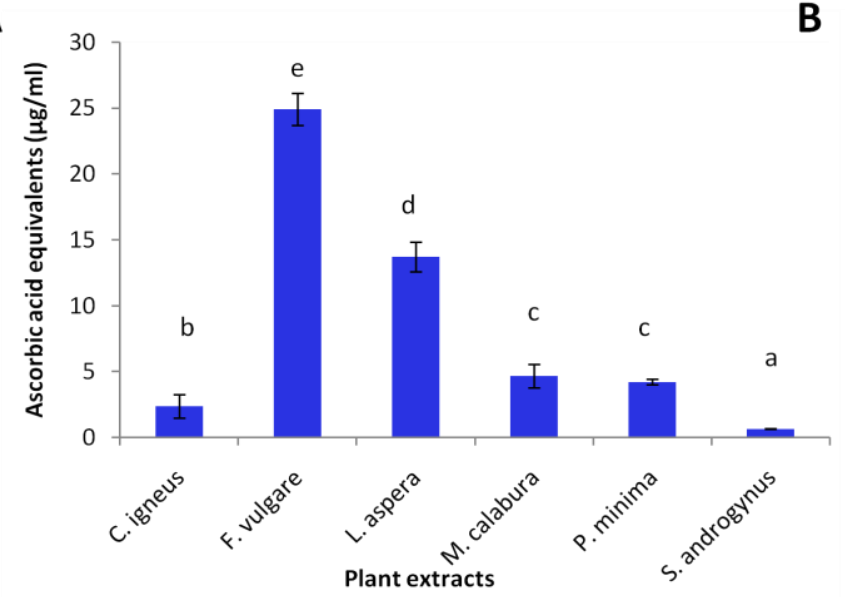

C

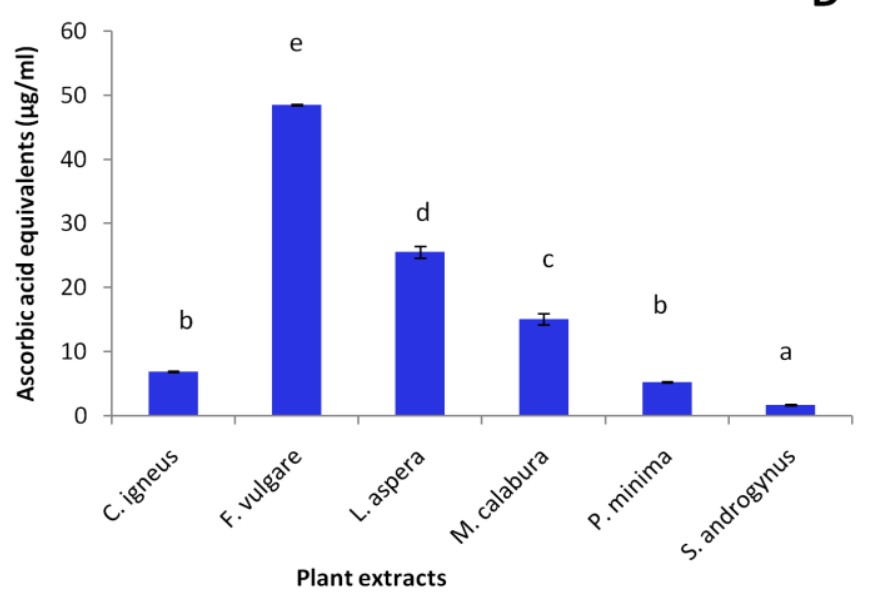

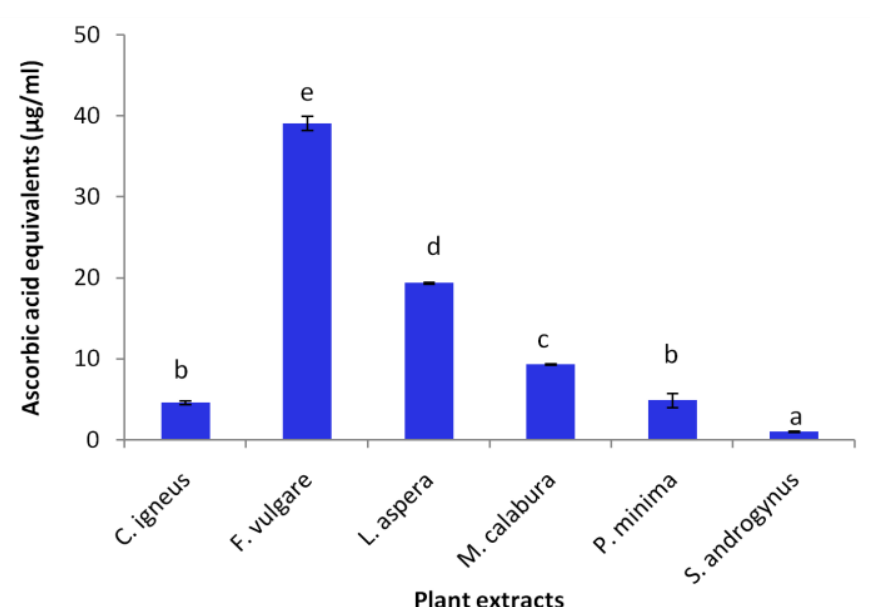

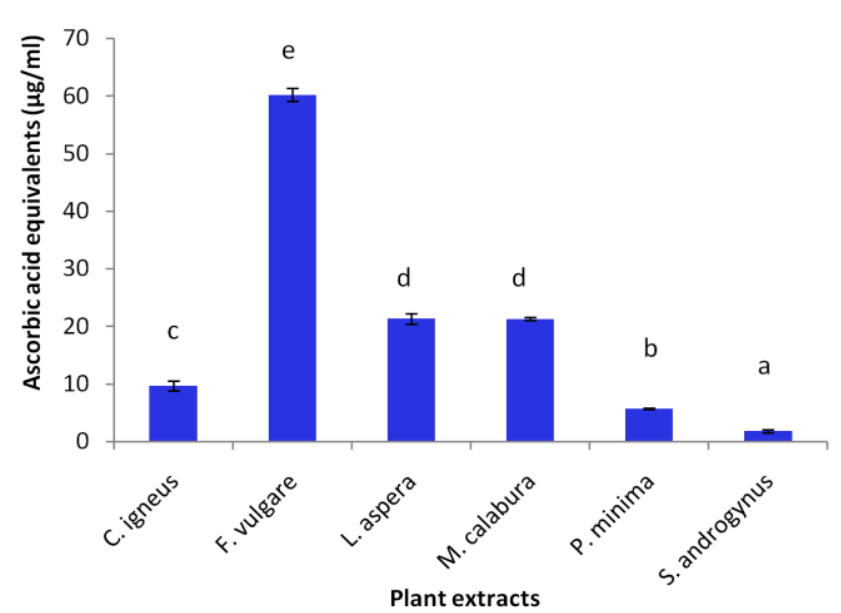

Fig. 2: Ferric reducing power of tested extracts at (A) $10 \mu \mathrm{g} / \mathrm{ml}$ (B) $15 \mu \mathrm{g} / \mathrm{ml}(\mathrm{C}) 20 \mu \mathrm{g} / \mathrm{ml}$ and (D) $25 \mu \mathrm{g} / \mathrm{ml}$ concentrations. Values are mean $\pm \mathrm{SD}(n=3)$. Data points indicated by different alphabets are significantly different from each other $(p<0.01)$.

\section{CONCLUSION}

This study provides the antioxidant activity of six plants used in indigenous traditional diet. The antioxidant activity of $F$. vulgare extract was higher than that of the reference antioxidant, ascorbic acid, thereby indicating its possible usage as a potential source of dietary antioxidants. Consumption of functional foods is thought to play a better role than neutraceutical consumption. Prolonged intake of neutraceuticals may impose a health concern because of their negative attributes such as presence of adulterants and inorganic pollutants. Most of the neutraceutical products need to be supported with clinical data, which is not the case for functional whole foods. In our study, the tested plant extracts were found to be antioxidant, thereby implementing their prospective use as nutritional whole food supplements for gaining health benefits against oxidative stress related disorders.

\section{ACKNOWLEDGEMENT}

The author Ashwini $\mathrm{P}$ acknowledges the postdoctoral fellowship provided by Yenepoya University, Mangalore.

\section{CONFLICT OF INTEREST}

Authors declare that they have no conflict of interest.

\section{REFERENCES}

Ali MS, Sayeed MA, Nabi M, Rahman MAA. In vitro antioxidant and cytotoxic activities of methanol extract of Leucas aspera leaves. J Pharmacogn Phytochem, 2013; 2: 8-13.

Banerjee D, Chakrabarti S, Hazra AK, Banerjee S, Ray J, Mukherjee B. Antioxidant activity and total phenolics of some mangroves in Sunderbans. Afr J Biotechnol, 2008; 7: 805-810.

Chothani LD, Vaghasiya HU. A phytopharmacological overview on Physalis minima Linn. Ind J Nat Prod Res, 2012; 3: 477-482.

Circu ML, Aw TY. Reactive oxygen species, cellular redox systems and apoptosis. Free Rad Biol Med, 2010; 48:749-762.

Gomathi R, Anusuya N, Manian S. A dietary antioxidant supplementation of Jamaican cherries (Muntingia calabura L.) attenuates inflammatory related disorders. Food Sci Biotechnol, 2013; 22: 787-794.

Kanchanapoom T, Chumsri P, Kasai R, Otsuka H, Yamasaki K. Lignan and megastigmane glycosides from Sauropus androgynus. Phytochem, 2003; 63:985-988.

Karpagasundari C, Kulothungan S. Free radical scavenging activity of Physalis minima Linn. leaf extract. J Med Plant Studies, 2014; 2: 59-64. 
Khalaf NA, Shakya AK, Al-Othman A, El-Agbar Z, Farah H. Antioxidant activity of some common plants. Turk J Biol, 2008; 32: 51-55.

Lu JM, Lin PH, Yao Q, Chen C. Chemical and molecular mechanisms of antioxidants: experimental approaches and model systems. J Cell Mol Med, 2010; 14: 840-860.

Nunez BR, Pruimboom L, Dijck-Brouwer DAJ, Muskiet FAJ. Lifestyle and nutritional imbalances associated with Western diseasescauses and consequences of chronic systemic low grade inflammation in an evolutionary context. J Nutr Biochem, 2013; 24: 11831201.

Oyaizu M. Studies on products of browning reaction-antioxidative activities of products of browning reaction prepared from glucosamine. Japan J Nutr, 1986; 44: 307-315.

Parejo I, Jauregui O, Sanchez F, Viladomat F, Bastida J, Codina C. Separation and characterization of phenolic compounds in fennel (Foeniculum vulgare) using liquid chromatography-negative electrospray ionization tandem mass spectrometry. J Agr Food Chem, 2004; 52: 36793687.

Pietta PG. Flavonoids as antioxidants. J Nat Prod, 2000; 63:1035-1042.

Prieto P, Pineda M, Aguilar M. Spectrophotometric quantitation of antioxidant capacity through the formation of a phosphomolybdenum complex: specific application to the determination of vitamin E. Anal Biochem, 1999; 269: 337-341.

Purkayastha S, Narain R, Dahiya P. Evaluation of antimicrobial and phytochemical screening of fennel, Juniper and Kalonji essential oils against multidrug resistant clinical isolates. Asian Pac J Trop Biomed, 2012; 2:1625-1629.

Rahman K. Studies on free radicals, antioxidants and co factors. J Clin Interven Aging, 2007; 2: 219-236.
Raman N. 2006. Phytochemical Techniques. New Indian Publishing Agencies, New Delhi.

Rather MA, Dar BA, Sofi SN, Bhat BA, Qurishi MA. Foeniculum vulgare: A comprehensive review of its traditional use, phytochemistry, pharmacology, and safety. Arab J Chem, 2012.Doi: 10.1016/j.arabc.2012.04.011.

Sadhu SK, Okuyama E, Fujimoto H, Ishibashi M. Separation of Leucas aspera, a medicinal plant of Bangladesh, guided by prostaglandin inhibitory and antioxidant activities. Chem Pharm Bull, 2003; 5: 595-598.

Saha MR, Hasan AMR, Akter R, Hossain MM, Alam MS, Mazumder MEH. In vitro free radical scavenging activity of methanol extracts of the leaves of Mimusops elengi Linn. Bangladesh J Vet Med, 2008; 6: 197-202.

Sataraddi SR, Nandibewwor ST. Biosynthesis, characterization and activity studies of silver nanoparticles by (Costus igneus) insulin plant extract. Der Pharmacia Lettre, 2012; 4:152-158.

Sharma PC, Yelne MB, Dennis TJ. 2000. Database on medicinal plants used in Ayurveda. AYUSH, New Delhi.

Sindhe AM, Bodke YD, Chandrashekar A. Antioxidant and in vivo antihyperglycemic activity of Muntingia calabura leaves extracts. Der Pharmacia Lettre, 2013; 5: 427-435.

\section{How to cite this article:}

Ashwini Prabhu, Madhushree M, Rekha Punchappady Devasya. Phytochemical constituents and antioxidant activities of some plants commonly used in Indian traditional diet. J App Pharm Sci, 2015; 5 (11): 108-112. 